\title{
Ego-Strength and Self-Concept among Adolescents: A Study on Gender Differences
}

\author{
Nayanika Singh ${ }^{1 *}$, Anmol Anand ${ }^{2}$
}

\section{ABSTRACT}

Self-concept refers to an individual's thoughts, ideas, views, images and/or perceptions about him/herself. This comprises of social or personal identity of an individual and his/her personality traits. A person having a positive self-concept will have a positive image of him/herself maintaining the congruency between the real self (who s/he really is) and the ideal self (who s/he wants to become) on the contrary individuals having a negative image of self suffer discrepancy between the real and the ideal self. Ego-strength is the extent of effectiveness with which our ego works in regulating the impulses and adjusting to the environment. It seeks balance while delaying the gratification of needs. Individuals low on ego-strength lack motivation and confidence believing themselves to be incompetent whereas people high on ego-strength are motivated, resilient and confident seeking to fulfill challenges by believing in themselves and their abilities. This investigation was an attempt to study the effect of gender on self-concept and ego-strength among adolescents, aged 18-22 years. The sample consisted of 120 adolescents (60 females and 60 males) randomly selected from private colleges of Chandigarh. Tools used were C-Factor of 16- PF ( Cattell \& Eber, 1962) which measures the whole range of personality (Factor C i.e. emotional stability vs. high ego strength) and Six- Factor Self-Concept Scale (SFSCS; Stakes, 1994) that assesses the self-concept and perceptions of an individual regarding him/herself across six domains/constructs i.e. Task accomplishment, morality, vulnerability, power, giftedness \& likeability. The hypothesis stated that: a) female adolescents will be higher on self-concept as compared to the male adolescents age ranging from 18-22 years and b) the female adolescents will be higher on ego-strength as compared to their male counterparts. Findings of the study indicated: a) That female adolescents were higher on self-concept as compared to male adolescents age ranging from 18-22 years b) There was no significant difference in the ego-strength among the female and male adolescents significantly proving the first hypothesis true.

Keywords: Gender, Adolescents, Self-concept, Ego-strength.

Adolescents: Adolescence is referred to as the age during which the individual transforms from a child to an adult, puberty marks the onset of adolescence. The changes that every individual goes through are social, physiological, psychological, behavioral, cognitive, developmental and moral. The rate of change and the degree varies on the basis of gender as well, it is seen that girls mature earlier to boys.

\footnotetext{
${ }^{1}$ Assistant Professor, Department of Psychology, Shaheed Udham Singh Group of Institutes, Tangori, Mohali

2 Third Year Student, Department of Psychology, D.A.V College, Sector-10, Chandigarh

(C) 2015 I N Singh, A Anand; licensee IJIP. This is an Open Access Research distributed under the terms of the Creative Commons Attribution License (http://creativecommons.org/licenses/by/2.0), which permits unrestricted use, distribution, and reproduction in any Medium, provided the original work is properly cited.
} 
At the biological level the individual beings develop secondary sexual characteristics and become aware of their body parts for example: girls by the growing size of their breasts and boys by the change in their voice etc.

The cognitive level consists of transformation including high reasoning and logical skills, wisdom, risk taking etc.

Social changes include increasing attraction for the opposite sex, loyalty towards peers, clashes with the parents and so on.

Vis-à-vis the psychological changes, now different psychologists view adolescence phase as significantly overcoming different challenges. G. Stanley Hall, the first president of the American Psychological Association was the pioneer in using and explaining the term adolescence which he viewed as the time of internal issues and conflicts in his publication

'Adolescence' (1904). Sigmund Freud suggested that the conflicts faced by adolescents are universal in nature and depended on the biological front. Erik Erickson gave the concept of identity formation and identity crisis during this stage of life. They all agree to the fact that this period is full of conflicts, upheavals, inner turmoil and transformation from a child to an adult.

Since, adolescents go through a variety of changes when it comes to their choice of clothes, food and sexual preferences, it is also remarkable to notice that the degree of the self-concept and egostrength changes as well. They are the most easily convinced and influenced by the people of their own age. Children start forming perceptions about themselves and their abilities at early stages and it determines the course of their life, yet it is possible to change the same with conscious efforts. For example, adolescents confine strongly in their peers, if they get accepted by the classmates and other people they develop a positive self-concept and high ego-strength if they cannot then their perception of self is negative and the ego-strength is low. The difference also lies in the self-concept and the ego-strength based on gender.

Self-Concept: It refers to the ideas, beliefs, thoughts, perceptions one holds of oneself. It caters to the answer, 'Who am I?' (Myers, 2009) and the answer depends on various factors; physical description, social roles, personality traits or existential material. The concept of self is a result of self-schemas which are the patterns in which we either summarize or store the knowledge of the self. Self evolves through interaction with self and others as the inclination of human beings towards communication is undeniable. For example; I am a good baker, I am an obedient student, I am a bad dancer, I get embarrassed at social gatherings etc.

Carl Rogers and Abraham Maslow (Humanistic School of Psychology) were the pioneers in establishing the notion of Self-Concept and is important for Self-Actualization (theory given by 
Maslow) i.e. to reach one's maximum potential in order to become a fully functioning person. "The organism has one basic tendency and striving - to actualize, maintain, and enhance the experiencing organism.” (Rogers, 1951).

Rogers argued that there are three components of self-concept namely1. Self-Image: This refers to the perceptions we have of ourselves. People may have a positive or a negative self-image. For example; I am good at singing (positive), I am easily embarrassed because of my weight (negative). We also tend to have inflated self-image i.e. I may believe that I am a really attractive person even when I am an average looking person. 2. Self-esteem: It is also known as self-worth and as the word indicates self-esteem refers to how we value our own worth. People can be either high or low on self-esteem. For example; an optimistic person who has confidence in his abilities is high on self-esteem whereas a person who lacks confidence, keeps worrying and is nearly a pessimist is low on the same. 3. Ideal Self: In simple words it refers to the way we want to see ourselves, what we would like to become. The focus is on the future outcome of the desired results. Congruence between the two helps the individual to self-actualize. However, if there is a discrepancy between the ideal and the real self, the person undergoes frustration and in extreme cases excessive anxiety. For example; A healthy person wishes to lose weight but is unable to, his real self (healthy) interferes with his ideal self (thin) causing frustration.

Mead (1934) suggested that it was the self-concept which differentiated human beings from animals as it allows self-interaction. Human beings have global ideas about themselves but the more specific ones form their ideas of self (self-concept).

There are cultural and gender differences when it comes to self-concept. In the western societies the focus is primarily on the individual and then the society, individual is considered more important (individualistic) whereas in the Asian societies there's and interdependence between the individual self and the society (Collectivistic). Girls prefer dyadic interactions (one-to-one) whereas boys prefer group activities.

Ego-strength: Ego-strength refers to the ability or the capability of an individual to showcase resilience, face challenges, remain emotionally stable and deal effectively when encountered with stressful or frustrating situations it is the way we maintain a healthy communication with the self and others. (Researches mention that ego strength comprises of the ego defense mechanisms like repression, rationalization, denial etc. that help us deal with the reality.). Usually the ego-strength is built during the first few years of life however it is never too late to build them on your own, one can certainly do that!

Symonds (1951) defines ego strength as the efficiency of the ego in regulating impulses and mastering the environment. Ego strength is the capacity for sustaining emotional equilibrium while waiting or working for later gratification. In other words it is a measure of the 
effectiveness with which the ego is performing its tasks of adapting to the demands of reality. A well-functioning healthy mind is the one where there is harmony between id, ego and superego by Engler (2014).

A person can be either high or low on ego-strength:

1. Low ego-strength: People showing lack of motivation to overcome obstacles, not wishing to move out of their comfort zones or are lazy are low on ego-strength. They have distorted thinking patterns which compel them into believing that they just can't do it, it's not their cup of tea or probably that they lack the resources and are delicate. Reality haters, such unrealistic patterns cause anxiety and stress as the person believes that the problems will go away themselves without their having to do anything about the same. Inflated self-worth when appreciated and feeling belittled when criticized etc. are few of the many characteristics of people low on ego-strength. Basically following avoidance approach.

2. High on ego-strength: People who are motivated enough to overcome obstacles, always striving for the better and acknowledging their feelings be it guilt, anger etc., are empathetic and remain positive despite the adversity of the situation are high on ego-strength. It is not difficult for them to say 'NO' to others and have a positive self-worth. They face tensions but are willing to change the situation and improving upon it to eliminate the stress. They believe in, 'No matter what life goes on'. Such individuals follow a 'learning' approach.

\section{RELATIONSHIP BETWEEN SELF-CONCEPT AND EGO-STRENGTH}

From the above mentioned we come to know that ego-strength is nothing but our ability to face successfully the challenge be it a social, psychological, cultural or developmental difficulty whereas self-concept refers to the images, notions or perceptions about ourselves. Ego-strength plays a crucial role in forming our self-concept (personal or social), this implies that people with high ego-strength have a positive self-concept for example: child scores well in his exams perceives himself as intelligent, such individuals have confidence in themselves and their abilities, they want to work harder, achieve more however people with low ego-strength have a negative self-concept for example: kid lagging behind in studies thinks of himself as a failure, they lack confidence and the consequently the motivation to work hard.

\section{REVIEW OF LITERATURE}

Kuhns (2011) conducted a study to investigate 'Adolescent Identity: Improving Student SelfConcept through Service Learning' among adolescents. Sample consisted of 28 high school students (17-18 years old) 15 from service-learning and 13 from traditional classrooms. Research methods included the content of survey instrument and parents consent form. Quantitative data collected using Self-Perception Profiles for Adolescents by Harter (1998) and qualitative data consisted two sets of open ended questions and demographic information. It was found that service-learning had a positive influence on self-concept of students and participants in the 
service-learning classroom described their fellow mates and teachers more positively than those in traditional classrooms.

Mishra (2013) conducted a study to analyze the self-concept and ego-strength of 80 visually impaired and the sighted students (14-18 years old) of two special schools and one regular school using the Children's Self-concept scale by Alhuwalia and Ego-strength by Hasan. Pearson's coefficient value and T-ratio were used and it was found that there is: a) positive relationship between ego-strength and self-concept b) ego-strength of the sighted students was higher than that of the visually impaired and c) self-concept of sighted students was higher than that of visually impaired.

Mirshekari, Chanaq and Zahed (2014) conducted an investigation to study the relationship between Ego-strength, Self-control and Self-esteem among 330 male and female students of University of Shahed'. The tools used included questionnaires Psychology of ego's strength, Eysneck's self-esteem, and self-control scale, and also demographic information (gender, school, education, age, and marital status, etc). Pearson's co-efficient value and T-ratio were used and it was found that there is: a) a correlation between all the elements b) Ego-strength was higher in women as compared to men c) Components of ego's strength care, love, loyalty, competence and hope were higher in women as compared to men d) Difference between the male and female selfcontrol and self-esteem was not significant.

The above review indicates that there is dearth of review of literature on the cumulative impact of self-concept and ego-strength among adolescents aged 18-22 years emphasizing particularly gender differences. This is one such attempt conducted in the Indian set-up.

\section{OBJECTIVES}

To study the effect of gender on the self-concept among adolescents, age ranging 18-22 years.

To study the effect of gender on the ego-strength among adolescents, age ranging 18-22 years.

\section{HYPOTHESIS}

Female adolescents aged 18-22 years will be higher on self-concept as compared to male adolescents.

Female adolescents aged 18-22 years will be higher on ego-strength as compared to male adolescents.

\section{METHODOLOGY}

Sample: The sample size for the current study consisted of 120 adolescents (60 males and 60 females) age ranging 18-22 years, randomly selected from private colleges of Chandigarh. 


\section{Tools:}

i) C-Factor of 16-PF (Cattell \& Eber, 1962):

The 16 PF inventory was constructed by Cattell to cover the whole range of individual's personality in terms of the most fundamental dimensions which comprehensively span the entire range of personality characteristics in people. Factor- $C$ (i.e. emotional stability vs. high ego strength) comprised of 26 items (13 each from Form (A) and Form (B) of the 16 PF). The items have been combined to make standardized working instrument for measuring ego strength. Though items of any scale from either A or B Forms for independent use of the scale are considered reliable and psychologically meaningful but in order to increase the precision and reliability, more items from both the Forms A and B were combined for use. The items are given a score of 2, 1, 0 according to the norms mentioned in the scoring key. Score on each item is added further to obtain a composite score.

\section{ii) Six-Factor Self-Concept Scale (SFSCS; Stakes, 1994):}

The SFSCS is a 36-item multidimensional scale designed to evaluate the self-concept and cognitive self-perceptions of individuals using descriptive adjectives/phrases across six domains/constructs (i.e. Task accomplishment, morality, vulnerability, power, giftedness \& likeability). Each phrase is rated on a scale ranging from 1 (Never or almost never true of you) to 7(Always or almost always true of you). The composite score for the test consists of a cumulative score on task accomplishment, morality, power, giftedness \& likeability minus the scores on the vulnerability dimension. The scale dimensions individually, after a period of six weeks yielded a test-retest reliability of the following; (Task accomplishment-.85), (Morality.74), (Vulnerability- .68), (Power- .85), (Giftedness- .72) and, (Likeability-.74). The test further yielded a coefficient of .97 for composite scores for a sample of both undergraduates and noncollege adults.

\section{Statistical Analysis:}

The response to various tests were scored according to the directions set in the manuals of the test and with the help of scoring keys. Means were computed for the different sets of data and independent sample t-test was applied to test the significance of mean difference between male and female adolescents from private colleges of Chandigarh.

\section{RESULTS AND DISCUSSION}

The present study was attempted to assess the impact of gender on the self-concept and egostrength of the adolescents age ranging 18-22 years randomly selected from private colleges of Chandigarh, for which the data was divided into two categories, self-concept and ego-strength among male and female adolescents. The independent t-test was applied for the purpose of statistical interpretation to test the significance of difference between these four means. Results and discussion of the present study are as follows: 
The following table (Table 1) indicates the effect of gender on the Self-concept among the adolescents

\begin{tabular}{|c|c|c|c|c|c|}
\hline \multirow{3}{*}{$\begin{array}{l}\text { TOTAL } \\
\text { SELF- } \\
\text { CONCEPT } \\
\text { SCORE }\end{array}$} & GENDER & $\begin{array}{l}\text { NUMBER } \\
\text { OF } \\
\text { ADOLESCE } \\
\text { NTS }\end{array}$ & MEAN & $\begin{array}{l}\text { STANDARD } \\
\text { DEVIATION }\end{array}$ & T-VALUE \\
\hline & FEMALES & 60 & 134.26 & 16.3 & \multirow{2}{*}{2.674} \\
\hline & MALES & 60 & 124.3 & 23.51 & \\
\hline
\end{tabular}

Significant at $(0.05=1.98)(\mathrm{df}=119)$

Results summarized in Table 1 indicate the effect of gender on the self-concept among the male and female adolescents, aged 18-22 years. The mean value for females was found to be 134.26 while for the males it was found to be 124.3. The t-value was found 2.674, which was significant at the level of 0.05 , indicating that gender has a significant effect on the self-concept of both males and females among adolescents therefore our first hypothesis (i.e. Females adolescents aged 18-22 years will be higher on self-concept than the males adolescents aged 18-22 years) stands

accepted.

The following table (Table 2) indicates the effect of gender on Ego-strength among adolescents

\begin{tabular}{|l|l|l|l|l|l|}
\hline $\begin{array}{l}\text { Total } \\
\text { Ego-strength } \\
\text { Score }\end{array}$ & GENDER & $\begin{array}{l}\text { NUMBER } \\
\text { OF } \\
\text { ADOLESCE } \\
\text { NTS }\end{array}$ & MEAN & $\begin{array}{l}\text { STANDARD } \\
\text { DEVIATION }\end{array}$ & T-VALUE \\
\cline { 2 - 6 } & FEMALES & 60 & 26.73 & 4.28 & 1.7122 \\
\cline { 2 - 6 } & MALES & 60 & 25.41 & 4.08 & \\
\hline
\end{tabular}

No significant differences

Results summarized in Table 2 indicate the effect of gender on ego-strength among the female and male adolescents, aged 18-22 years. The mean value of both female and male adolescents were found to be 4.28 and 4.08 respectively while the t-value came out to be 1.7122 thereby indicating that there are no significant differences at the level of 0.05 and no significant difference on the ego-strength among female and male adolescents aged 18-22 years. Therefore our second hypothesis (i.e. The ego-strength among female will be higher than male adolescents aged 18-22 years) is rejected. 
The plausible explanations for female adolescents having a higher level of self-concept than the male adolescents may be because of the Movement of Women Empowerment implying a dramatic change in the role of women from merely being confined to four walls of the house to getting educational and occupational exposure as well as a considerable augmented awareness thereby enhancing the self-concept. Females now have become independent having their own identity to which they can relate. Also, they have a commendable zeal to rise. Moreover females being rightly assertive, are able to maintain a work-life balance which further assists them in enhancing the self-concept.

Since there was no significant difference of ego-strength among the female and male adolescents this shows that they are almost equally resilient in maintaining their emotions efficiently. Also, males have been found to be supportive and cooperative in assisting their female counterparts. The present study is one of its kind in the Indian set-up. However, more research on diverse population and newer variables is needed to substantiate the same.

\section{Suggestions and Recommendations:}

The following can be some of the suggestions and recommendations to improve the self-concept and ego-strength of the adolescents-

1. Positivity- It is important to do anything that you do or feel with positivity. We, humans can't stop thinking or acting so we might as well be positive in our approach.

2. Realistic expectations- One must set goals and expectations that are realistic and achievable so that conquering them becomes an accomplishment. Setting unrealistic goals and failing at them causes depression, loss of faith in oneself and anxiety.

3. Adjustment of Self-image- One must be able to change one's self perception and image for it is very important to know oneself, love oneself and be true to oneself.

4. Decrease the idea of perfection- There should be goals and ideals however, the idea of perfection should be decreased as it creates unnecessary problems.

5. Stop comparing yourself to others- Every individual is capable and talented but those capabilities and talents may not match those of the others. Individual differences must be kept in mind so comparison with oneself is advisable and considered healthy.

6. Increasing patience- Being patient is an important aspect in being resilient, one should patiently work upon one's personality and aspects that require a change.

7. Individuals must try to become more aware and conscious of their-self, try to surround themselves with positive and motivational movies, books etc.

8. Introspection- This is another way to realize ones strengths and weaknesses thereby working on these areas by being completely honest with oneself. 


\section{REFERENCES}

Cattell, R.B., \& Eber, H.W. (1962). The Sixteen personality factor questionnaire. Champaign, Illinois: IPAT.

Engler, B. (2014). Personality Theories: An Introduction. Belmont: Wadsworth Cengage Learning

Guimond, Serge; Chatard, Armand; Martinot, Delphine; Crisp, Richard J.; Redersdorff, Sandrine (2006). "Social comparison, self-stereotyping, and gender differences in self-construal". Journal of Personality and Social Psychology. Volume 90.(2): 221-242

Hall, G. S. (1904). Adolescence: Its psychology and its relations to physiology, anthropology, sociology, sex, crime, religion, and education (Vols. I \& II). New York: D. Appleton \& Co.

Kuhns, J.E. (2011). Adolescent identity: improving self-concept of students through service learning. (Master's Thesis). Retrieved from ProQuest Dissertations and Theses. (UMI No. 0736M10124)

Mirshekari, H.R.; Chanaq, A.R.;Zahed, M. (2014). "The Investigation of the relationship between ego-strength, self-control and self-esteem among students of University of Shahed”.Indian Journal Of Fundamental and Applied Life Sciences. Volume 4.(S3): p. 1303-1308)

Mishra, V. (2013). “A study of self-concept in relation to ego-strength of sighted and visually impaired students”.International Journal on New Trends in Education and their Implications. Volume 4(9): p. 203-207

Myers; David, G. (2009). Social psychology. (10 ${ }^{\text {th }}$ edition). New York: McGraw-Hill Higher Education

Rogers, C. (1951). Client-Centered Therapy, London: Constable

Stake, J.E. (1994). Developments and Validation of the Six- Factor Self Concept Scale for Adults. Educational and Psychological Measurement. Volume 54: p 56-71

Symonds, P.M. (1951). The Ego and the Self. New York: Appleton- Century- Crofts, Inc. 